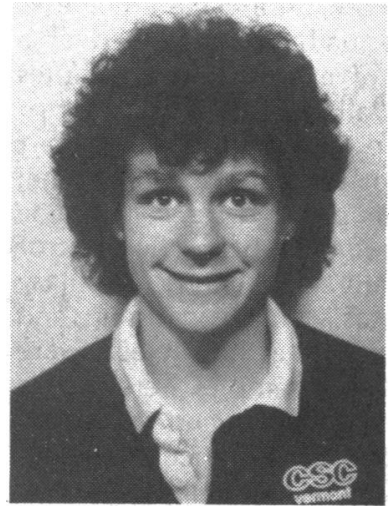

Mary E. Cheetham

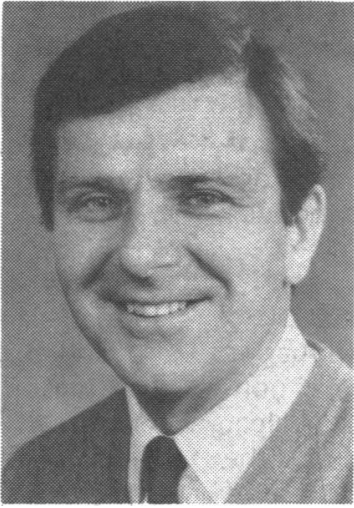

C. Williams

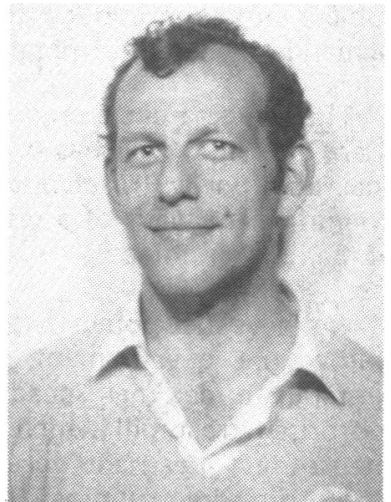

H. K. A. Lakomy

\title{
A LABORATORY RUNNING TEST: METABOLIC RESPONSES OF SPRINT AND ENDURANCE TRAINED ATHLETES
}

Mary E. CHEETHAM, BSc, C. WILLIAMS, BSc, MSc, PhD and H. K. A. LAKOMY, BSc, MA

Dept. of Physical Education and Sports Science, University of Technology, Loughborough, Leics. LE11 $3 T U$

\section{ABSTRACT}

A laboratory-based sprint running test has been devised to examine the performance characteristics and metabolic responses of an individual to $\mathbf{3 0}$ seconds of maximal exercise. A non-motorised treadmill was used so that the individual was able to sprint at his own chosen speed and also to vary his speed as fatigue occurred. The treadmill was instrumented so that the chosen speeds as well as the equivalent distance travelled could be monitored by micro-computer throughout the test. The test-retest reliability of the procedure was investigated with 14 recreational runners who performed the test on different days. A good correlation $(r=0.93)$ was found between the values obtained for peak running speeds on the two occasions.

In an attempt to establish whether or not this test could be used to identify the differences in the performance characteristics of highly trained individuals, the responses to the test of eleven sprint trained and eleven endurance trained athletes were examined. The sprint trained athletes covered a greater distance $(162.2 \pm 5.95 \mathrm{~m}$ vis $153.51 \pm 12.32 \mathrm{~m} ; \mathrm{p}<0.01)$ and had higher blood lactate concentrations $(16.52 \pm 1.23 \mathrm{mM}$ vis $12.98 \pm 1.77 \mathrm{mM} ; \mathrm{p}<0.01)$ than the endurance trained athletes. Therefore this laboratory sprint running test offers an additional way of investigating human responses to brief periods of high intensity exercise.

Key words: Sprinting, Metabolism, Testing.

\section{INTRODUCTION}

The physiological and metabolic responses to prolonged submaximal exercise have been well documented (Milvey, 1977; Williams et al, 1984) whereas relatively little information is available for exercise of maximal intensity and brief duration. There are at least two reasons for this relative lack of information on the responses to brief high intensity exercise which are (1) the absence of an acceptable exercise protocol and (2) the absence of convenient methods for assessing the metabolic response to maximal exercise.

During prolonged submaximal exercise energy expenditure and the relative contributions of fat and carbohydrate to metabolism can be assessed from non-invasive determinations of the respiratory responses to exercise (Krogh and Lindhard, 1920; Jansson, 1982). However, during brief periods of maximal exercise the accurate assessment of oxygen consumption $\left(\mathrm{VO}_{2}\right)$ is difficult and a metabolic interpretation of the respiratory responses to this type of activity is invalid because it is non-steady state exercise (Hermansen, 1969). Furthermore, methods by which maximal exercise can be performed and the powef output asséssed under laboratory conditions have not been readily available. Recently a cycle ergometer test protocol has been proposed which offers a method of determining the power output developed during maximal exercise. Bar-Or and colleagues (Bar-Or et al, 1977) have suggested a protocol which involves monitoring the pedal frequency of the ergometer while the subject pedals as fast as possible for 30 seconds against a resistance which is adjusted for body weight $(75 \mathrm{~g} / \mathrm{kg}$ body weight). From these observations the peak and

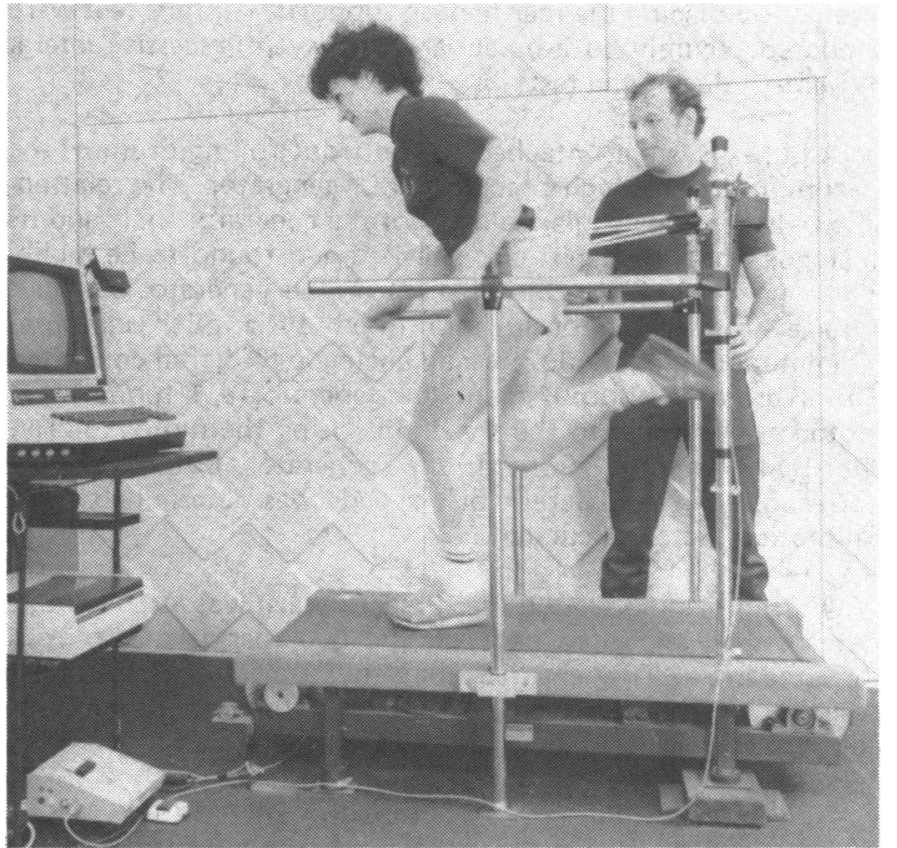

A laboratory running test using a non-motorised treadmill.

mean power outputs as well as the fall in peak power output can be monitored. The 30 second duration of the exercise period is short enough to elicit a maximum effort from each 
subject but long enough to ensure that there is a significant demand on anaerobic metabolism (Boobis et al, 1983).

The Wingate cycle ergometer test, as it has become known, (Bar-Or et al, 1977) has been well received as a useful test of anaerobic power (MacDougal et al, 1983). However, there are no equivalent ways of assessing the responses to brief periods of maximal running.

We have developed a test procedure which allows us to follow the development of fatigue while an individual is running at maximal speed. This procedure employs a nonmotorised treadmill which allows the individual to self-select the running speed and accelerate or slow down at will as is the case during free running. In order to examine the potential of this running test we assessed the performances of two groups of highly trained individuals who, by the nature of their sports, use different training methods. One of the groups was comprised of endurance trained cross-country skiers, while the other group were mainly sprint-trained Rugby players.

\section{METHOD}

\section{Subjects}

The subject participating in the study were 11 members of the British Cross Country Ski (CCS) team, who train predominantly by distance running, and 11 club standard Rugby Union three quarters (RB) i.e. backs, who train for, and participate in, a game which demands both speed and endurance. The physical characteristics of the subjects are shown in Table I. A non-motorised treadmill (Woodway model $A B$ ) was used for the tests because it allows an individual to sprint at his own speed, and to change speed as fatigue occurs.

Table I Physical characteristics of the subjects (mean \pm S.D.)

\begin{tabular}{lcccc}
\hline & $\mathrm{n}$ & Height $(\mathrm{cm})$ & Weight $(\mathrm{kg})$ & Age $(\mathrm{yrs})$ \\
\hline Rugby backs & 11 & $177.95 \pm 5.12$ & $79.5 \pm 6.73$ & $20.55 \pm 1.13$ \\
\hline $\begin{array}{l}\text { Cross-country } \\
\text { skiers }\end{array}$ & 11 & $174.88 \pm 10.47$ & $68.3 \pm 8.39$ & $22.20 \pm 3.30$ \\
\hline
\end{tabular}

The treadmill, which normally slopes backwards, was levelled by placing the rear feet on supports. All four feet were anchored securely to a baseboard to prevent excessive lateral movement during the test.

A pulley system, attached to the front rolling drum of the treadmill, drove a high precision D.C. generator. The relationship between the angular velocity of the generator shaft and its analogue voltage output was checked and found to be highly linear $\left(r^{2}=99.8 \%\right)$. During a sprint the generator's output voltage was continuously monitored by a microcomputer (Commodore model 4032) via an analogue-to-digital converter. To calibrate the output from the generator a 1 h.p. electric motor was coupled to the treadmill. Using the motor to drive the belt (length $2.93 \mathrm{~m}$ ) the generator output voltage corresponding to different belt speeds was determined and a calibration factor calculated.

A strap passing around the subject's waist was attached to a flat cross-bar mounted between the two rear vertical rails of the treadmill. This ensured that the subjects maintained a constant position on the treadmill. The strap height could be adjusted by raising or lowering the cross-bar.

At the conclusion of each sprint the averaged one second values of treadmill speed were calculated and displayed by the computer.

\section{Protocol}

The subjects were familiarised with treadmill running on a day prior to the test and following an overnight fast completed two 30 second periods of fast leg work on a cycle ergometer (25 and $40 \mathrm{~km} / \mathrm{hr}$ against a $1 \mathrm{~kg}$ load) which served as a preparation for the maximal bout of exercise. Five minutes after this standardised warm-up an "all-out" 30 second sprint was performed on the non-motorised treadmill. A rolling start was used which required the subject to run at a submaximal speed of $8 \mathrm{~km} / \mathrm{hr}$ for a few moments prior to the sprint. The subjects were instructed to run maximally from the start of the test and were encouraged verbally throughout. Capillary blood samples were obtained 4 minutes after the warm up, and 1 and 5 minutes following the sprint while the subjects were sitting on an examination couch. These samples were deproteinised in $2.5 \%$ perchloric acid centrifuged and frozen at $-20^{\circ} \mathrm{C}$. Analyses for blood lactate and blood glucose concentrations were completed at a later date using the methodology described by Maughan (1982).

Statistical analysis of the differences between mean values of results obtained in this study was achieved using a pooled t-test. The reproducibility of the test protocol was examined in a sub-study involving 14 recreational ( 8 female and 6 male) runners, who completed two $\mathbf{3 0}$ second sprints on separate days following the standardised familiarisation procedure.

\section{RESULTS}

The treadmill sprint test was found to be highly reproducible as reflected by the results of the sub-study which showed that the mean ( \pm S.D.) peak running speeds for sprints 1 and 2 were $5.49( \pm 0.60) \mathrm{m}^{-1}$ and $5.43( \pm 0.65) \mathrm{m}^{-1} \mathrm{~s}^{-1}(r=0.93)$ respectively. The mean values for the distance moved by a point on the treadmill belt during the 30 seconds exercise period were $144.43( \pm 13.26) \mathrm{m}$ and $144.12( \pm 15.04) \mathrm{m}$ for sprints 1 and 2 respectively $(r=0.96)$. However, the percentage fall in speed was more variable with a correlation coefficient of 0.73 and mean values of $23.81( \pm 7.76) \%$ and $21.84( \pm 7.62) \%$ for the two sprints. For one subject the coefficient of variation for 5 repeated sprints over a 10 day period was $2.5 \%$.

The speed profiles generated during treadmill sprinting by the two groups of athletes in the present study are shown in Figure 1. This graph shows the relationship between running speed and time, and illustrates the faster running speeds of the Rugby backs throughout the time course of the test. A summary of the results of the tests for the two groups of athletes is shown in Table II. These results show that the Rugby backs covered a significantly $(p<0.05)$ greater distance than the cross-country skiers during the sprint test. Whilst peak running speed was higher for the Rugby backs than skiers the difference was not statistically significant. The

Speed profiles developed during treadmill sprinting.

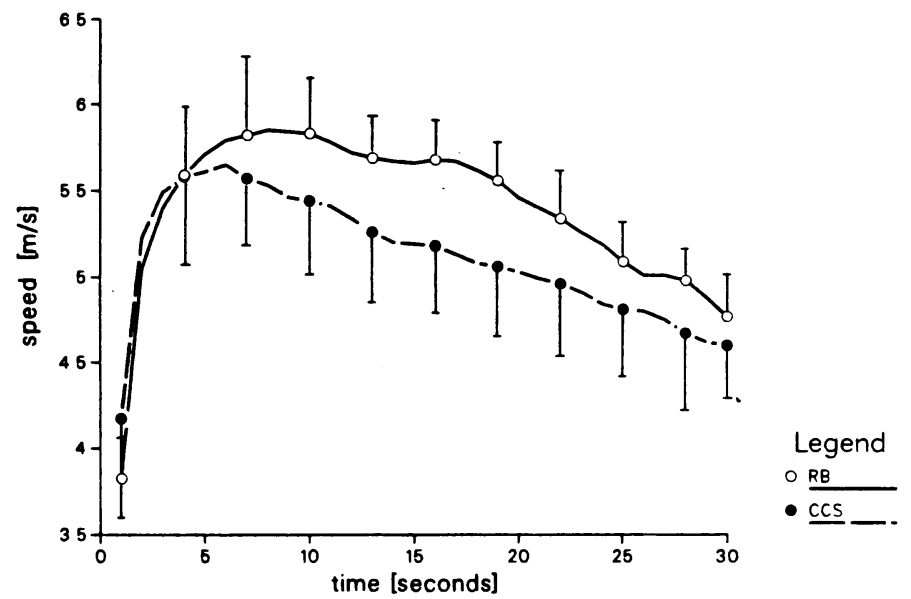

Fig. 1: shows the mean ( \pm S.D.) running speeds $(\mathrm{m} / \mathrm{s})$ for the 11 Rugby backs (RB) and the 11 cross-country skiers (CCS) during the 30 seconds of treadmill sprinting. 
Table II Peak speeds $\left(\mathrm{m} \cdot \mathrm{s}^{-1}\right)$, distance run $(\mathrm{m})$ and fatigue index (\% fall in speed) of Rugby backs and cross country skiers during the treadmill sprint test (means \pm S.D.)

\begin{tabular}{lccc}
\hline & $\begin{array}{c}\text { peak speed } \\
\left({\left.\mathrm{m} . \mathrm{s}^{-1}\right)}^{-1}\right.\end{array}$ & $\begin{array}{c}\text { distance run } \\
(\mathrm{m})\end{array}$ & $\begin{array}{c}\text { fall in speed } \\
(\%)\end{array}$ \\
\hline \begin{tabular}{l} 
Rugby backs \\
\hline $\begin{array}{l}\text { Cross-country } \\
\text { skiers }\end{array}$
\end{tabular}$\quad 5.96 \pm 0.35$ & $162.20 \pm$ & $5.95^{*}$ & $19.90 \pm 4.74$ \\
\hline \multicolumn{4}{l}{ denotes significantly different at $p<0.05$ level }
\end{tabular}

fatigue index, defined as the percentage fall in speed from fastest to slowest values, was the same for both groups.

The changes in blood lactate and blood glucose concentrations following treadmill sprinting are shown in Figure 2. Compared with the post warm-up values $(1.37 \pm 0.80 \mathrm{mM}$, RB; $1.48 \pm 0.50 \mathrm{mM}$, CCS) both groups of athletes showed large and significant $(p<0.01)$ increases in blood lactate concentrations at both one minute $(10.05 \pm 2.97 \mathrm{mM}, \mathrm{RB} ; 7.78 \pm$ $1.51 \mathrm{mM}, \mathrm{CCS})$ and 5 minutes $(17.89 \pm 1.12 \mathrm{mM}, \mathrm{RB} ; 14.49 \pm$ $1.79 \mathrm{mM}, \mathrm{CCS}$ ) following the sprint.

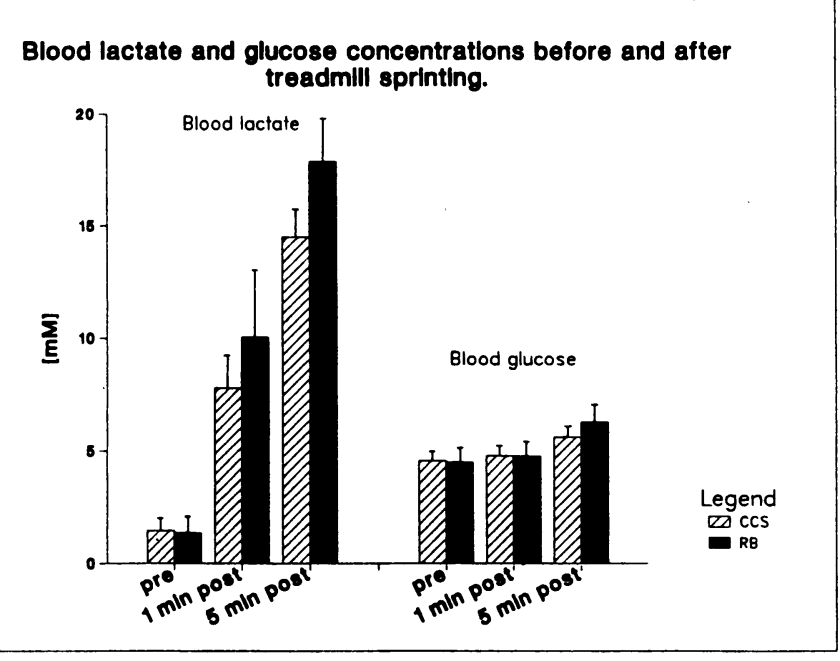

Fig. 2: shows the mean ( \pm S.D.) concentrations (mM) of blood lactate and blood glucose before (pre), 1 minute and 5 minutes after 30 seconds of treadmill sprinting for the 11 Rugby backs (RB) and the 11 cross-country skiers (CCS).

There were also increases in blood glucose concentrations above the post warm-up values for both groups of athletes (4.49 $\pm 0.55 \mathrm{mM}, R B ; 4.55 \pm 0.30 \mathrm{mM}, \mathrm{CCS})$ but only the samples taken 5 minutes $(6.28 \pm 0.71 \mathrm{mM}, \mathrm{RB} ; 5.62 \pm 0.41$ $\mathrm{mM}, \mathrm{CCS}$ ) after the sprint were significantly greater than the post warm-up values $(p<0.01)$.

\section{DISCUSSION}

The speed profiles generated during treadmill sprinting demonstrate that, as with sprint cycling, maximal velocities are reached during the first few seconds of the sprint. Thereafter, there is a considerable decrement in performance during the remainder of the test. The faster running speeds of the Rugby backs when compared to the skiers may reflect a greater anaerobic power output for this group of games players. This finding would be consistent with the higher power outputs generated by sprint trained as opposed to endurance trained athletes during maximal cycling tests (Crielaard and Pirnay, 1981). It is recognised however, that the inherent inertia and resistance of the treadmill belt has to be overcome by the runner. Preliminary observations of video recordings of subjects sprinting on the treadmill suggest that each runner adopts an optimum sprinting style, with little advantage being gained from over-leaning against the restraining strap (Lakomy, unpublished). Nevertheless, the greater body weights of the Rugby players, compared with the skiers, may have had some contribution to the differences in performances. However the relative contribution of body weight to the performance, during this running test, is unclear and so is currently being investigated.

Although there were significant differences in performances between the Rugby backs and cross-country skiers, there were even greater differences in the changes in blood metabolites between the two groups.

The games players had a significantly greater increase in blood lactate and blood glucose concentrations following treadmill sprinting than the skiers. This was unlikely to be due to differences in the time course of the changes in the concentrations of blood metabolites, as Thomson and Garvie (1981) found that the blood lactate concentration of both marathon runners and sprinters reached peak values at 4.2 minutes post exercise following a brief treadmill run to exhaustion. Peak blood lactate concentration, following 30 seconds maximal cycling, has been shown to occur at approximately 5 minutes post exercise (MacDonald et al, 1983; Wootton, 1984). The higher blood lactate concentrations of the Rugby backs are consistent with the results of other authors who have reported that athletes involved in sprint type activities achieve higher blood lactate concentrations than endurance trained athletes after maximal exercise (Thomson and Garvie, 1981; Serjested 1982; Ohkuwa et al, 1984). However, it is not always clear whether these reported results simply reflect the superior performances of these athletes. To examine whether or not the larger increases in blood lactate concentration were simply a function of the greater distance covered by the Rugby backs, blood lactate concentrations were expressed in terms of distance covered i.e. $\mathrm{mM}$ per metre run (Table III). This correction indicated that for each metre run, the Rugby backs had a significantly ( $p<0.01$ ) higher blood lactate concentration than the skiers. This may be reflection of the higher percentage of fast twitch fibres found in the muscle of athletes involved in sprint type activities and the enhanced activity of glycolytic enzymes (Costill et al, 1976). A further possibility may be that the endurance trained athletes were able to make a greater aerobic contribution to energy supply during the sprint than the games players. While in the present study the $\mathrm{VO}_{2}$ max values of the Rugby players were not determined, a previous study, of this same population of individuals, reported $\mathrm{VO}_{2}$ max values of 57.1 ( \pm 3.9 ) $\mathrm{ml}^{-\mathrm{kg}^{-1} \mathrm{~min}^{-1}}$ (Hazeldine et al, 1983). The $\mathrm{VO}_{2}$ max values for the crosscountry skiers, was determined in the present study and found to be 69.0 ( \pm 4.1$) \mathrm{ml}_{\mathrm{kg}} \mathrm{k} \mathrm{min}^{-1}$. Therefore it is relevant to note that Thomson and Garvie (1981) found that during one minute's running, marathon runners were able to obtain a $37.4 \%$ contribution and sprinters only a $27.7 \%$ contribution from aerobic metabolism to the total energy expenditure.

Table III Blood lactate concentrations (mM) following maximal treadmill sprinting and blood lactate concentration per metre run $(\mathrm{mM} / \mathrm{m}$ ) for Rugby backs and cross-country skiers (mean \pm S.D.)

\begin{tabular}{lll}
\hline & La. $(\mathrm{mM})$ & La. $(\mathrm{mM} / \mathrm{m})$ \\
\hline Rugby backs & $16.52 \pm 1.23^{* *}$ & $0.102 \pm 0.009^{* *}$ \\
\hline Cross-country skiers & $12.98 \pm 1.77$ & $0.085 \pm 0.010$ \\
\hline
\end{tabular}

It is important to recognise the fact that whilst the Rugby backs did have a significantly greater increase in blood lactate concentration, both in absolute terms and in relation to distance run, the changes in blood lactate and glucose concentrations of both groups, following treadmill sprinting, were nevertheless considerable. This is possibly a reflection of the maximal rate of work during the test, which demands a large contribution from anaerobic glycolysis. Both the increase in blood lactate and blood glucose concentrations following treadmill sprinting were greater than those recorded following 
30 seconds of maximal cycling exercise (MacDonald et al, 1983). This may be a result of a larger muscle mass being utilised during sprint running as compared to sprint cycling. The disturbance to blood glucose was particularly marked when one considers that the subjects were running for only 30 seconds. This may be a reflection of the influence of exercise-induced increases in catecholamine concentration (MacDonald et al, 1983; Brooks et al, 1985).

In summary, the 30 second maximal sprint test on a nonmotorised treadmill has proved a valuable and reliable model for the examination of the performance and metabolic responses of athletes to sprint running in a laboratory. The performance test did differentiate between the two groups of athletes, and with further modification, particularly to take into account the influence of body weight, it could provide a useful method for estimating the anaerobic power of individuals during sprint running.

\section{References}

Bar-Or, O., Dotan, R. and Inbar, O., 1977 "A 30 sec. all-out ergometer test - its reliability and validity for anaerobic capacity". Israel J. Med.Sci. 13: 126-130.

Boobis, L., Williams, C. and Wootton, S. A., 1983 "Human muscle metabolism during brief maximal exercise", J.Physiol. 338: 21-22P.

Brooks, S., Cheetham, M. E. and Williams, C., 1985 "Endurance training and the catecholamine response to maximal exercise". J. Physiol. 361: 81P.

Costill, D. L., Daniels, J., Evans, J. A., Fink, W., Krahenbuhl, C. and Saltin, B., 1976 "Skeletal muscle enzymes and fiber composition in male and female track athletes". J.appl.Physiol. 40: 149-54.

Crielaard, J. M. and Pirnay, F., 1981 "Anaerobic and aerobic power of top athletes". Eur.J.appl.Ṕhysiol. 47: 294-300.
Hazeldine, R. J., Macdonald, K. P. and Williams, C., 1983 "An evaluation of the physical fitness of University Rugby Football players". J.Sports Sciences 1: 138-139.

Hermansen, L., 1969 "Anaerobic energy release". Med.Sci.Sports 1: 32-38.

Jansson, E., 1982 "On the significance of the respiratory exchange ratio after different diets during exercise in man". Acta Physiol.Scand. 114: 103-110.

Krogh A and Lindhard, J, 1920 "The relative value of fat and carbohydrate as sources of muscular energy". Biochem.J. 14: 290-363.

MacDonald, 1. A., Wootton, S. A., Munoz, B., Fentem, P. H. and Williams, C., 1983 "Catecholamine response to maximal anaerobic exercise". In: Biochemistry of exercise. Int. Series on Spt Sciences. Vol. 13. Ed.: H. G. Knuttgen, J. A. Vogel and J. R. Poortmans. Human Kinetic Publishers, Champaign, pp. 787-793.

MacDougal, J. D., Wenger, H. A. and Green, H. J., 1983 "Physiological testing of the elite athlete". Pub. The Canadian Association of Sports Sciences, Winsor, Ontario.

Maughan, R. J., 1982 "A simple rapid method for the determination of glucose, lactate, pyruvate, alanine, 3-hyroxybutarate and acetoacetate on a single 20 ul blood sample". Clin.Chim.Acta 122: 231-240.

Milvey, P. 1977 "The marathon: physiological, medical, epidemiological and psychological studies". Ann.N.Y.Acad Sci. 301: 1-1099.

Onkuwa, T., Kato, Y., Katsumata, K., Nakao, T. and Miyamura, M., 1984 "Blood lactate and glycerol after $400 \mathrm{~m}$ and $3000 \mathrm{~m}$ runs in sprint and long distance runners". Eur.J.appl.Physiol. 53: 213-218.

Serjersted O. M. Medbo, J. I. and Hermansen, L., 1982 "Metabolic acidosis and changes in water and electrolyte balance after maximal exercise". In: Metabolic acidosis. Ciba Foundation Symposium 87 Ed. J. Whelan and R. Porter. Pitman Medical, London pp. 153-167.

Thomson, J. M. and Garvie, K. J., 1981 "A laboratory method for determination of anaerobic energy expenditure during sprinting". Can.J.appl.Sports Sci. 6: 16-20.

Williams, C., Brewer, J. and Patton, A., 1984 "The metabolic challenge of the marathon". Brit.J.Sports Med. 18: 245-252.

Wootton, S. A., 1984 "The effect of diet and training on ability to perform maximal exercise in man". PhD thesis, Loughborough University of Technology.

\section{BOOK REVIEW}

Title: THE FOOT AND LEG IN RUNNING SPORTS

Editor: Robert P. Mack

Publishers: $\quad$ C. V. Mosby Co., St. Louis \&c., 1984

Price: $£ 31.50 \quad 184$ pages

This volume contains the review papers presented at a major orthopaedic meeting and a wealth of interesting discussion points in many of the main topics of current concern to running doctors.

There are contributions from Cavanagh, Mann, Bowerman, Jackson and Leach as well as Eriksson, Cooper and Ogilvie. Subjects covered include back pain, knee, foot and shin pain. Achilles injuries and compartment syndromes (or not, according to one contribution!). A brief piece on orthotics and shoe adjustment is woefully inadequate, but all the rest will stimulate all clinicians in the field.

It is gratifying to see how far clinical interest has followed the running movement and to be hoped that volumes such as this will play an important part in interesting enough clinicians to satisfy the largely unmet needs of the athletic patients.

The book is well produced, wide ranging, very readable, stimulating and controversial in the best sense. Thoroughly recommended. 